\title{
The influence of geochemistry on health risks to animals and humans in geographically localised livestock production systems
}

\author{
J.A. Meyer ${ }^{1}$, N.H. Casey $^{1}$ and J. Myburgh ${ }^{2}$ \\ ${ }^{1}$ Dept of Animal and Wildlife Sciences, University of Pretoria, South Africa; ${ }^{2}$ Dept of Community Herd Health, Faculty of \\ Veterinary Science, University of Pretoria, South Africa
}

\section{Introduction}

Research conducted for the Water Research Commission and the National Research Foundation concerning geochemistry related risk factors, and health implications, within communal livestock production systems in selected communities, revealed a high number of potentially hazardous constituents to occur within both surface and subterranean water sources. As a consequence of this, livestock may, both indirectly and directly, pose significant toxicological risk to the health of humans, dependent on the nature of the association between humans and animals. Recent advances in identifying the role of inorganic constituents on the epidemiology of non-differential clinical symptoms commonly observed in both animals and livestock have led to an increase in efforts to measure and assess the potential risk posed by geochemistry related factors. Communities relying on livestock for subsistence, particularly those within localised areas, are most at risk from the adverse effects due to the ingestion of inorganic constituents which may precipitate toxicities, deficiencies, and/or imbalances. This paper presents initial phase investigation results, which indicate the high probablity for mulitple ingestion routes of hazardous inorganic constituents for humans and livestock.

\section{Materials and Methods}

Risk assessments based on hydrochemistry of both subterranean and surface waters, shared by both humans and livestock, were conducted in selected high risk communities. This paper presents the results from four main areas: Hartebeeslaagte Community, Barolong Resettlement area, Jericho district and Immerpan District. The first three areas fall within the North Western Province, although spatially and geological vastly different, whilst the Immerpan District is located in the Northern Province, adjacent to Delftzyl Agricultural Research Station. Water samples were collected according to methods prescribed by the Institute for Soil, Climate and Water (ISCW), and were analysed by the ISCW for 46 WQCs. Samples were collected from the point of use, although in many instances either directly from the borehole, or reservoir, usually as a result of drought and/or the discontinued use of a water source due to suspected adverse effects. For some samples mercury was not quantified, due to sample preservation techniques for nitrate and nitrite determination. Risk assessments for livestock were conducted utilising a software program developed for the Water Research Commission, CIRRA Version 1.03 (Casey et al., 1998). For humans, risk assessments used local and international guidelines currently in use, including DWA\&F (1996), Quality of Water for Domestic Supplies (1998), USEPA (1998) and the WHO (1996). The main reason for using multiple guidelines was to obtain the full spectrum of inorganic constituents reported to influence human health. Relevant recommended mineral guideline ratios influencing main PHCs were also calculated.

\section{Results and Discussion}

Summaries of the results are shown in Tables 1 and 2. The following average As:Se ratio obtained in the Jericho region was 18.5, with a median value of 7.31 and a maximum value of 98.94 found.

Table 1. Summary statistics for important ratios influencing fluoride toxicity in the Jericho Communal Area (summer sampling phase 1999)

\begin{tabular}{ccccccc}
\hline Ratios & F:Ca & F:B & F:TDS & F:Sr & F:Mo & F:pH \\
\hline RGR & $>166.66$ & $>4.166$ & $>500.00$ & $<0.166$ & $<0.0067$ & $>1.333$ \\
Average & 34.8 & 253.6 & 0.202 & 0.207 & 0.282 & 11.4 \\
SD & 37.4 & 248.8 & 0.244 & 0.192 & 0.317 & 21.9 \\
Median & 29.1 & 178.9 & 0.169 & 0.134 & 0.208 & 5.06 \\
Minimum & 1.67 & 0.203 & $9 \mathrm{E}-04$ & 0 & 0 & 1.1 \\
Maximum & 142 & 803.8 & 0.705 & 0.63 & 1.049 & 80 \\
\hline
\end{tabular}

* = Recommended Guideline Ratio (WQC/F) 
(C) South African Society of Animal Science

Short paper and poster abstracts: $38^{\text {th }}$ Congress of the South African Society of Animal Science

Table 2 Summary statistics for the main PHCs and COCs identified from 41water samples collected in the Jericho Communal Area (summer sampling phase 1999)

\begin{tabular}{|c|c|c|c|c|c|c|c|}
\hline \multirow{2}{*}{$\begin{array}{c}\text { WQC } \\
\text { (n) }\end{array}$} & \multirow{2}{*}{$\begin{array}{c}\text { PHC } \\
386 \\
\end{array}$} & \multirow{2}{*}{$\begin{array}{c}\mathrm{COC} \\
68 \\
\end{array}$} & \multirow[t]{2}{*}{$\begin{array}{c}\text { Average } \\
(\mathrm{mg} / \mathrm{L})\end{array}$} & \multirow[t]{2}{*}{$\begin{array}{c}\mathrm{SD} \\
(\mathrm{mg} / \mathrm{L})\end{array}$} & \multirow[t]{2}{*}{$\begin{array}{c}\text { Median } \\
(\mathrm{mg} / \mathrm{L})\end{array}$} & \multicolumn{2}{|c|}{$\begin{array}{l}\text { Range } \\
(\mathrm{mg} / \mathrm{L})\end{array}$} \\
\hline & & & & & & Minimum & Maximum \\
\hline$\xi / W P$ & 9.414 & 1.658 & & & & & \\
\hline As & 8 & 0 & 0.039 & 0.074 & 0 & 0 & 0.288 \\
\hline $\mathrm{Sb}$ & 28 & 0 & 0.037 & 0.037 & 0.036 & 0 & 0.700 \\
\hline $\mathrm{Be}$ & 36 & 0 & 0.025 & 0.014 & 0.028 & 0 & 0.051 \\
\hline $\mathrm{Br}$ & 35 & 0 & 0.261 & 0.176 & 0.275 & 0 & 2.292 \\
\hline $\mathrm{Cd}$ & 30 & 1 & 0.046 & 0.045 & 0.038 & 0 & 0.186 \\
\hline $\mathrm{Cr}$ & 4 & 15 & 0.039 & 0.072 & 0.019 & 0.003 & 0.329 \\
\hline $\mathrm{F}$ & 11 & 1 & 1.087 & 0.747 & 0.53 & 0.01 & 7.77 \\
\hline $\mathrm{Hg}$ & 28 & 0 & 0.118 & 0.116 & 0.082 & 0 & 0.444 \\
\hline $\mathrm{Pb}$ & 24 & 1 & 0.026 & 0.024 & 0.021 & 0 & 0.090 \\
\hline $\mathrm{Mn}$ & 35 & 0 & 0.35 & 0.61 & 0.15 & 0.01 & 2.76 \\
\hline Mo & 20 & 5 & 0.055 & 0.052 & 0.049 & 0 & 0.204 \\
\hline $\mathrm{Se}$ & 30 & 0 & 0.752 & 0.685 & 0.711 & 0 & 2.292 \\
\hline $\mathrm{Te}$ & 28 & 1 & 0.209 & 0.202 & 0.199 & 0 & 0.700 \\
\hline $\mathrm{Tl}$ & 22 & 0 & 0.016 & 0.019 & 0.012 & 0 & 0.085 \\
\hline $\mathrm{Ti}$ & 12 & 0 & 0.433 & 1.025 & 0.1 & 0.033 & 4.531 \\
\hline TDS & 8 & 4 & 294.3 & 200.5 & 251 & 63 & 805 \\
\hline $\mathrm{Sr}$ & 0 & 32 & 0.254 & 0.268 & 0.149 & 0.034 & 1.137 \\
\hline $\mathrm{U}$ & 12 & 4 & 0.016 & 0.016 & 0.011 & 0 & 0.068 \\
\hline
\end{tabular}

\section{Discussion and Conclusion}

Most advances made in applied investigations in mineral related deficiencies, toxicities or imbalances, have utilised purified diets (Underwood \& Suttle, 1999), and the recognition of the importance of site-specific geochemical factors in altering the level at which adverse effects appear, and the nature of those effects, although fairly recent, is growing (Mills,1996; WHO, 1996). Concern for mineral toxicities is increasing (Underwood \& Suttle, 1999). A number of the trace minerals identified to be present at potentially hazardous concentrations include those identified as newer essential elements by Underwood \& Suttle (1999), namely, B, Cr, Ni, Mo, Sn and V. According to Plant et al., (1996) PHCs tend to have adverse effects at relatively low levels, and that all trace minerals are toxic if ingested at sufficiently high doses for sufficient periods of time, incorporating contextual toxicology. The communities investigated all rely on subsistence agriculture, and are at a greater risk of adverse effects due to trace mineral hazards (Plant et al., 1996). A primary reason for this is that the rural production systems investigated do not have potential risk attenuated by food and water sourced from multiple sources. Furthermore, drought is a common occurrence in these areas, which tends to restrict food and water supply to a greater degree, and can amplify local anomalies in soil, plant and water composition. Site-specific factors which increase risk for both user groups include bioaccumulation, bioconcentration, a high prevalence of sensitive high-risk user groups, involuntary ingestion of soil, and environmental antagonists (altitude, temperature). The shared utilisation of the water sources in the areas investigated pose both modelling and ethical concerns relating to the formulation and application of alleviator treatments which involve water treatment. The correlations obtained for PHCs increase the risk present due to either a lack of beneficial systemic synergistic ratios between trace minerals, or ratios which aid in increasing the uptake from the digestive system of harmful constituents, or decrease tubular reabsorption of mitigatory constituents. Correlations between $\mathrm{F}$, TDS, $\mathrm{Ca}, \mathrm{B}, \mathrm{Mo}, \mathrm{Sr}$ and $\mathrm{pH}$, all resulted in an increase in potential risk due to chronic fluorosis. A lack of desirable protective ratios was also found between $\mathrm{As}$ and $\mathrm{Se}$, and $\mathrm{Cu}$ and $\mathrm{Mo}$. 


\section{Conclusion}

Short paper and poster abstracts: $38^{\text {th }}$ Congress of the South African Society of Animal Science

In conclusion, the concentrations of PHCs in the water sources present a significant route of exposure, and when viewed in context of other geochemical factors on soil and plant concentrations, the estimation of total exposure from all sources is essential for a site-specific risk assessment and differential diagnosis to be conducted, which can enable contextual solutions to be formulated.

\section{Acknowledgements}

The support of the Water Research Commission and the Department of Community Herd Health at the Faculty of Veterinary Science, University of Pretoria, is gratefully acknowledged.

\section{References}

Casey, N.H. et al., 1998. Volume 1: Development and modelling. Report to the Water Research Commission. WRC Report No: K5/644/1/98. ISBN No: 1868457390

DWA\&F 1996. Department of Water Affairs and Forestry: South African Water Quality Guidelines (second edition). Volume 4: Agricultural Use: Livestock Watering.

Mills, C. F., 1996. Environmental Geochemistry and Health. Ed. Appleton, J. D., Fuge, R. and McCall, G. J. H., Geological Society Special Publication No. 113 pp 1 - 5.

Plant J. A. et al., 1996. . Environmental Geochemistry and Health. Ed. Appleton, J. D., Fuge, R. and McCall, G. J. H., Geological Society Special Publication No. 113 pp 7-22.

Quality of Domestic Water Supplies, 1998. Volume 1. Assessment Guide. Second edition. Second Print. Published by Water Research Commission, The Department of Water Affairs and Forestry, and The Department of Health.

Underwood, E.J, \& Suttle, N.F., 1999. The Mineral Nutrition of Livestock. 3rd Edition. Commonwealth Agricultural Bureaux. pp. 4 - 41.

USEPA, 1996. Environmental Protection Agency. Drinking water regulations and health advisories. Office of Water. USA..

WHO, 1996. World Health Organisation. Geneva. Guidelines for drinking-water. Volume 2. pp. 55-77. 